\title{
Effect of immunization against LHRH on isoforms of LH in the ovine pituitary
}

\author{
D. D. Zalesky ${ }^{1 *}$, B. D. Schanbacher ${ }^{2} \dagger$ and H. E. Grotjan ${ }^{1} \ddagger$ \\ ${ }^{1}$ Animal Science Department, University of Nebraska, Lincoln, NE 68583-0908, USA; and \\ ${ }^{2}$ USDA§, ARS, Roman L. Hruska US Meat Animal Research Center, PO Box 166, Clay Center, \\ NE 68933-0166, USA
}

\begin{abstract}
The role of LHRH in modulating intrapituitary LH content as well as the distribution of LH among its isoforms was examined in sheep. $\operatorname{Rams}(n=3)$ and wethers $(n=6)$ were actively immunized against an LHRH-human serum globulin conjugate. Pituitaries collected from these animals plus pituitaries from corresponding numbers of nonimmunized rams and wethers were extracted with a buffered saline solution containing protease inhibitors. Immunization markedly reduced total amounts of immunoreactive LH in the pituitary. An aliquot of each pituitary extract was desalted by flow dialysis against water and chromatofocused on a $\mathrm{pH}$ 10.5-7.0 gradient. Concentrations of $\mathrm{LH}$ in chromatofocusing fractions were determined by radioimmunoassay. LH in pituitary extracts resolved into nine peaks during chromatofocusing which were coded with letters beginning with the most basic isoform. The percentage of $\mathrm{LH}$ as the two most basic isoforms, $\mathrm{A}^{\prime}$ and $\mathrm{B}$, was similar $(P>0.05)$ in all treatment groups. Isoform $\mathrm{H}$ constituted a higher percentage $(P<0.05)$ of the $\mathrm{LH}$ in both castrate groups. Nonimmunized wethers had higher percentages of isoforms $C, D$ and $E(P<0.05)$ and lower percentages $(P<0.05)$ of the acidic isoforms (coded as peak $Z$ herein) than did other treatment groups. Thus, castration shifted the pattern of intrapituitary isohormones towards the more basic forms. Nonimmunized rams had a higher percentage $(P<0.05)$ of isoform $\mathrm{G}$ than did other groups. Isoform $\mathrm{F}$, the most abundant isoform, was present as a higher percentage $(P<0.05)$ in immunized rams and wethers than in nonimmunized animals. Hence, ablation of hypothalamic LHRH reaching the pituitary by active immunization not only markedly reduced the quantity of $\mathrm{LH}$ in the pituitary, but also altered the distribution of $\mathrm{LH}$ among its isoforms yielding a higher percentage of the most abundant isoform $\mathrm{F}$. Hypothalamic LHRH therefore not only increases the quantity of $\mathrm{LH}$ in the pituitary but also alters the pattern of intrapituitary isohormones by reducing the percentage present as isoform F. Furthermore, inputs from both the hypothalamus and gonads appear to regulate the distribution of intrapituitary isohormones with hypothalamic influences predominating.
\end{abstract}

\section{Introduction}

Luteinizing hormone-releasing hormone (LHRH), a neurohormone produced in the hypothalamus, stimulates the secretion of LH by the anterior pituitary (Schally et al., 1973). Recent studies have revealed that LHRH also regulates the biosynthesis of LH by stimulating the expression of the genes that encode the subunit peptides (Andrews et al., 1988; Mercer et al., 1988). Hence, both the biosynthesis and secretion of pituitary LH are LHRH dependent. Consequently, reproductive function

${ }^{*}$ Present address: South Dakota State University, West River Research and Extension Center, Rapid City, SD 57701, USA.

†Present address: Route 1, Box 4A, Clay Center, NE 68933, USA.

†Correspondence and reprint requests.

§Mention of names is necessary to factually report on available data; however, the USDA neither guarantees nor warrants the standard of the product, and the use of the name by USDA implies no approval of the product to the exclusion of others that may also be suitable.

Received 21 December 1992 is impaired when stimulation of the pituitary gland by LHRH is interrupted. Gonadal steroids modulate hypothalamic inputs into the pituitary and thus are also involved in the regulation of both the synthesis of LH subunit peptides (Wise et al., 1985; Landefeld et al., 1989) and the secretion of LH (Schanbacher and Ford, 1977; D'Occhio et al., 1983; Day et al., 1984; Imakawa et al., 1986).

In a variety of species, LH does not exist as a single molecular entity but rather is heterogeneous; both the intrapituitary (Keel et al., 1987; Zalesky and Grotjan, 1991a, b) and secreted (Zalesky and Grotjan, 1991b) hormone exist as a family of molecular forms. This heterogeneity results, in part, because the oligosaccharides attached to the subunit peptides of $\mathrm{LH}$ have variable structures (reviewed by Baenziger and Green, 1988; Grotjan, 1989). LH heterogeneity is subject to endocrine regulation because gonadal steroids alter the distribution of LH among its isoforms (Keel et al., 1987; Stumpf et al., 1992a). 
Active immunization against LHRH has proved valuable in assessing the function of the hypothalamic-pituitary axis (Clarke et al., 1978; Chappel et al., 1980; Schanbacher, 1982; Falvo et al., 1986). No unintended or disruptive consequences are incurred as may be the case with certain other methods that can be used to block hypothalamic inputs into the pituitary. In this study, active immunization was used to determine how the pattern of intrapituitary LH isoforms is modulated by LHRH. Both intact and castrated ovine males were examined to characterize potential interactions between hypothalamic and gonadal inputs.

\section{Materials and Methods}

\section{Animals and pituitary collection}

Eighteen sexually mature Suffolk rams were assigned to this study. Nine rams were actively immunized against LHRH using a LHRH-human serum globulin conjugate as described by Schanbacher (1982) and Chase et al. (1988). Three s.c. booster injections were administered to the nine immunized rams, with the last given approximately six weeks before slaughter. The remaining nine rams served as nonimmunized controls. Six control and six immunized rams were castrated approximately four months before slaughter. Success of immunizations was evident as atrophied testes at castration or slaughter. All immunized and nonimmunized animals were killed at the USDA Meat Animal Research Center abattoir in Clay Center, NE, USA. Pituitaries were collected on ice, trimmed of extraneous blood vessels and frozen in liquid nitrogen within $15 \mathrm{~min}$ of death.

\section{Extraction of pituitary tissue}

Pituitaries were homogenized in $150 \mathrm{mmol}$ sodium chloride ${ }^{-1}$ $50 \mathrm{mmol}_{\text {Tris }} \mathrm{l}^{-1}(\mathrm{pH} 7.4)$ containing $0.5 \%(\mathrm{v} / \mathrm{v})$ Triton X-100 to completely solubilize LH and a cocktail of protease inhibitors ( $5 \mathrm{mmol}$ disodium EDTA $^{-1}, 1 \mathrm{mmol}$ phenylmethylsulfonyl fluoride $\mathrm{l}^{-1}, 200 \mathrm{U}$ aprotinin $\mathrm{ml}^{-1}$ and $5 \mu \mathrm{g}$ leupeptin $\mathrm{ml}^{-1}$ ). One millilitre of buffer was used per $100 \mathrm{mg}$ tissue. Extracts were clarified by centrifugation at $100000 \mathrm{~g}$ for $1 \mathrm{~h}$, divided into aliquots and frozen at $-70^{\circ} \mathrm{C}$ until use.

\section{Chromatofocusing}

Chromatofocusing was performed with reagents obtained from Pharmacia/LKB Biotechnology (Piscataway, NJ) using methods described by Zalesky and Grotjan (1991a, b) and Grotjan et al. (1991). Briefly, $10 \mathrm{ml}$ columns $(0.7 \mathrm{~cm} \times 26 \mathrm{~cm}$; Kontes, Vineland, NJ) of PBE-118 resin were equilibrated in $25 \mathrm{mmol}$ triethylamine- $\mathrm{HCl}^{-1}, \mathrm{pH}$ 11.0. Aliquots of pituitary extracts $(0.5 \mathrm{ml}$ representing $50 \mathrm{mg}$ tissue equivalents) were desalted by flow dialysis against distilled water using membranes with a 6-8000 molecular weight cutoff (Spectra/por 1; Spectrum Medical Industries, Inc., Los Angeles, CA). After dialysis, extracts were supplemented with Pharmalyte 8-10.5$\mathrm{HCl}, \mathrm{pH} 7.0$, to $2 \%(\mathrm{v} / \mathrm{v}), 2 \mathrm{mg}$ of cytochrome $\mathrm{C}$ and $2 \mathrm{mg}$ myoglobin (to monitor the efficacy of separation). After sample application, $\mathrm{pH}$ 10.5-7.0 gradients were developed with Pharmalyte $8-10.5-\mathrm{HCl}$ diluted 1:45 with distilled water and adjusted to $\mathrm{pH} 7.0$ with $6 \mathrm{~mol} \mathrm{HCl}^{-1}$. Columns were eluted at $5 \mathrm{ml} \mathrm{h}^{-1}$ and $1.5 \mathrm{ml}$ fractions were collected $(n=80)$ until a stable, lower limiting $\mathrm{pH}$ was attained. Proteins bound to the column at the lower limiting $\mathrm{pH}$ were eluted with $1.0 \mathrm{~mol} \mathrm{NaCl}$ $\mathrm{I}^{-1}$ and collected as an additional twenty $1.5 \mathrm{ml}$ fractions. Fractions were neutralized by addition of $0.15 \mathrm{ml} 1.1 \mathrm{~mol}$ Tris $1^{-1}$ ( $\mathrm{pH} \mathrm{7.0)}$. Columns were re-equilibrated with at least 50 to 60 column volumes of triethylamine between samples. All buffers were degassed before use and contained $5.0 \%$ glycerol to enhance LH recovery. Recovery of immunoreactive LH from the columns averaged $90 \%$.

\section{Radioimmunoassays}

Immunoreactive $\mathrm{LH}$ in tissue extracts and chromatofocusing samples were quantified by double antibody radioimmunoassays. The standard preparation used in the assays was oLHDNW-HSN-10-124 (provided by D. N. Ward, Houston, TX). The first antibody used was anti-hCG $\alpha$ oLH $\beta$-EG7N (Zalesky and Grotjan, 1991a) and the purified hormone preparation, oLH-LER-1374A (provided by L. Reichert, Albany, NY), was used for iodination. The anti-oLH antibody specifically reacts with oLH and oLH $\beta$ but exhibits minimal crossreactivity with uncombined alpha subunits or other pituitary hormones. Iodinated hormone was prepared with immobilized oxidant (Iodobeads; Pierce, Rockford, IL) (Grotjan et al., 1991). The immunoassay buffer contained $150 \mathrm{mmol} \mathrm{NaCl} 1^{-1}, 50 \mathrm{mmol}$ Tris $\mathrm{l}^{-1}$ (pH 7.4), $5 \mathrm{mmol}$ disodium EDTA $\mathrm{l}^{-1}, 1 \mathrm{mg}$ gelatin $\mathrm{ml}^{-1}$ and $0.1 \%(\mathrm{w} / \mathrm{v})$ sodium azide. Sensitivity of the assays was $0.042 \mathrm{ng} \mathrm{ml}^{-1}$. Intra- and interassay coefficients of variation were $5.5 \%$ and $8.8 \%$, respectively.

\section{Statistical analysis}

The percentage of each immunoreactive $\mathrm{LH}$ isoform present in each pituitary extract was calculated. Percentage values were subjected to arc sine transformation (arc sine of the square root of the percentage) prior to statistical analysis so that they would be normally distributed (Snedecor and Cochran, 1967). Oneway analysis of variance (SAS, 1985) was used to determine whether there were statistically significant differences in the distribution of LH isoforms among treatment groups. When there were differences, Duncan's new multiple range tests (SAS, 1985) were used to determine which means were different. Probabilities of less than 0.05 were considered statistically significant.

\section{Results}

Mean pituitary weights for nonimmunized rams (intact), immunized rams (intact-I), nonimmunized wethers (castrate) and immunized wethers (castrate-I) were $0.56 \pm 0.03 \quad(n=3)$, $0.61 \pm 0.08(n=3), 0.57 \pm 0.08(n=6)$ and $0.70 \pm 0.05$ $(n=6) \mathrm{g}$, respectively, and were not significantly different among the groups. Mean content of LH within the pituitary was greater $(P<0.05)$ for nonimmunized rams $(1041 \pm 246 \mu \mathrm{g})$ 


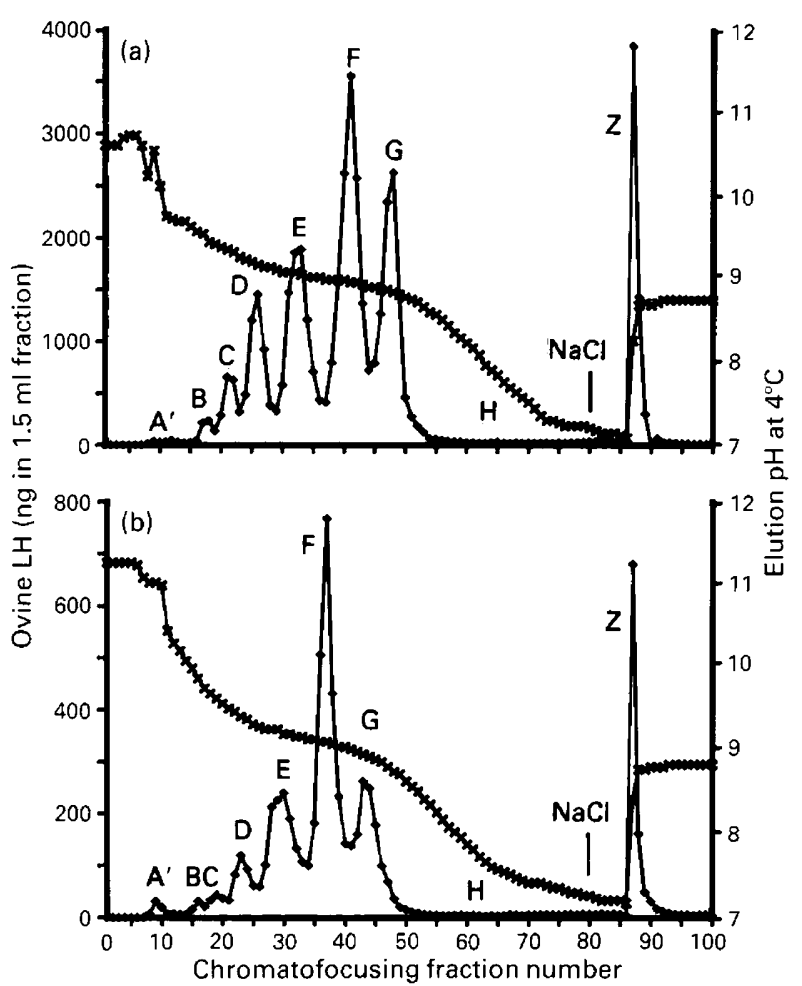

Fig. 1. Representative chromatofocusing elution profiles $(\bullet)$ of the immunoreactive LH in ovine pituitary extracts from (a) nonimmunized and (b) immunized rams. Extracts were chromatofocused on $\mathrm{pH} 10.5-$ 7.0 gradients. Eluent fractions $(n=80)$ were collected until a stable lower limiting $\mathrm{pH}$ was attained. Proteins bound to the columns at the lower limiting $\mathrm{pH}$ were eluted with $1 \mathrm{~mol} \mathrm{NaCl}{ }^{-1}$ and collected as an additional 20 fractions. Isoforms were coded with letters beginning with the most basic form.

and wethers $(458 \pm 123 \mu \mathrm{g})$ than for immunized rams $(37 \pm 13 \mu \mathrm{g})$ or wethers $(29 \pm 7 \mu \mathrm{g})$.

Nine isoforms of $\mathrm{LH}$ could be identified when pituitary extracts from animals in each treatment group were chromatofocused on $\mathrm{pH} 10.5-7.0$ gradients. Representative chromatofocusing profiles for nonimmunized (intact) and immunized (intact-I) rams are shown (Fig. 1), and those representing nonimmunized (castrate) and immunized wethers (castrate-I) are illustrated (Fig. 2). The mean percentages of the isoforms within each treatment group are also presented (Table 1). No significant differences were observed between the treatment groups $(P>0.05)$ for the percentages of $\mathrm{LH}$ present as the two most basic isoforms $A^{\prime}$ and $B$. Isoform $H$ was more abundant $(P<0.05)$ in wethers and nonimmunized wethers than in immunized or nonimmunized rams. The mean percentage of $\mathrm{LH}$ eluting as isoforms $\mathrm{C}, \mathrm{D}$ and $\mathrm{E}$ was greater and the mean percentage of $\mathrm{LH}$ eluting as the acidic isoforms, coded as peak $\mathrm{Z}$ herein, was lower $(P<0.05)$ for wethers than for other treatment groups. Thus, castration induced a shift in the distribution of LH isoforms towards basic forms. Nonimmunized rams had a higher percentage $(P<0.05)$ of isoform $\mathrm{G}$ than did other groups. A higher percentage of the most predominant isoform, $\mathrm{F}$, was identified in both immunized rams and wethers $(P<0.05)$ compared with nonimmunized males. Hence, LHRHimmunoneutralization had a pronounced affect and increased the percentage present as isoform $F$.

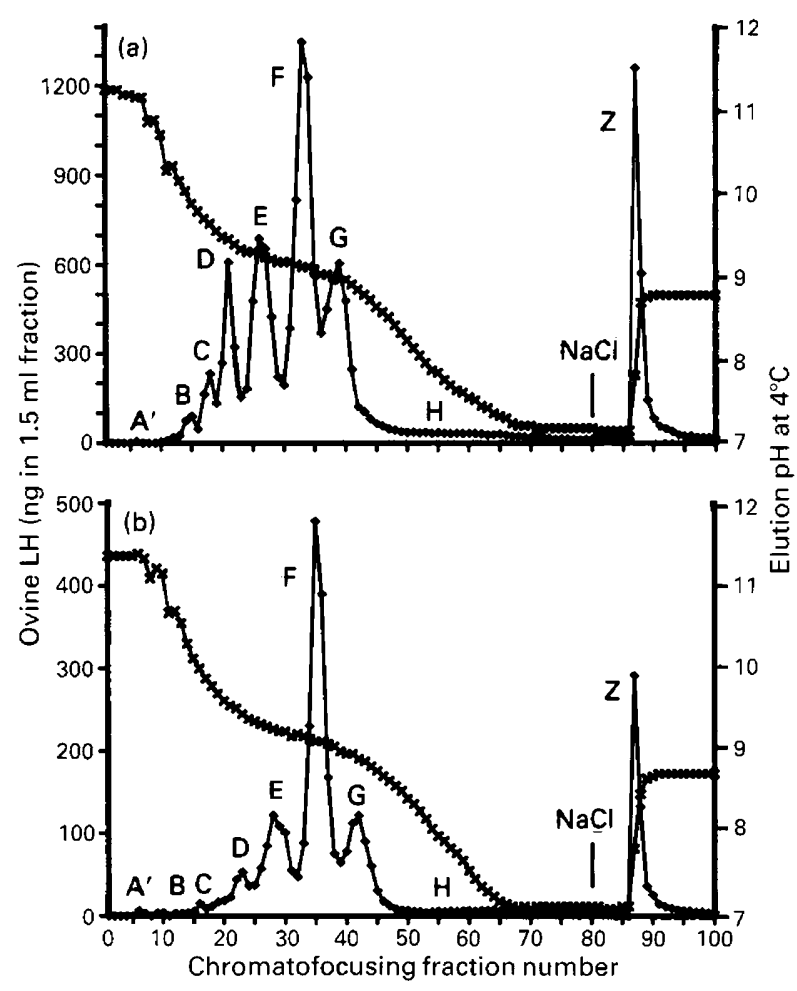

Fig. 2. Representative chromatofocusing elution profiles ( $\downarrow$ ) of immunoreactive LH in ovine pituitary extracts from (a) nonimmunized and (b) immunized wethers. Extracts were chromatofocused on $\mathrm{pH} 10.5-7.0$ gradients. Eluent fractions $(n=80)$ were collected until a stable lower limiting $\mathrm{pH}$ was attained. Proteins bound to the columns at the lower limiting $\mathrm{pH}$ were eluted with $\mathrm{I} \mathrm{mol} \mathrm{NaCll}{ }^{-1}$ and collected as an additional 20 fractions. Isoforms were coded with letters beginning with the most basic form.

\section{Discussion}

LHRH stimulates the biosynthesis and secretion of $\mathrm{LH}$ and thus plays an essential role in the cascade of events that lead to normal reproductive function. Gonadal feedback mechanisms modulate the action of LHRH on the pituitary. One component of gonadal feedback is alteration of the distribution of $\mathrm{LH}$ among its isoforms (Keel et al., 1987; Stumpf et al., 1992a). Consequently, it was of interest to determine how LH heterogeneity was altered by hypothalamic LHRH as well as to determine how hypothalamic and gonadal inputs interact. Chronic and specific inhibition were achieved by using immunizations to ablate the input of LHRH into the pituitary. Potential interactions between hypothalamic and gonadal inputs were evaluated by examining immunized rams and wethers.

Active immunizations against LHRH markedly reduced the LH contents of the pituitaries of rams and wethers to approximately $3.5 \%$ and $6.3 \%$, respectively, of those of corresponding nonimmunized animals even though pituitary weights among the four treatment groups were similar. These results confirm that immunizations were effective and are consistent with the known stimulatory actions of LHRH on LH synthesis. The pituitary LH contents for nonimmunized wethers were less than those for rams. Unlike the situation in many species, castration reduces the amount of $\mathrm{LH}$ in the ovine pituitary even though peripheral concentrations are increased (Schanbacher and Ford, 1977; Keel et al., 1987). 
Table 1. Distribution of isoforms of $\mathrm{LH}$ in the ovine pituitary

\begin{tabular}{lccccc}
\hline Isoform & Intact & Intact-I & Castrate & Castrate-I & Elution pH $\mathrm{H}^{\mathrm{a}}$ \\
\hline $\mathrm{A}^{\prime}$ & $0.4 \pm 0.1$ & $1.5 \pm 0.7$ & $0.4 \pm 0.1$ & $1.2 \pm 0.3$ & $10.7 \pm 0.1$ \\
$\mathrm{~B}$ & $0.9 \pm 0.3$ & $0.9 \pm 0.1$ & $1.7 \pm 0.2$ & $0.8 \pm 0.3$ & $10.1 \pm 0.1$ \\
$\mathrm{C}$ & $2.5 \pm 0.9$ & $1.6 \pm 0.4$ & $4.8 \pm 0.6^{*}$ & $2.4 \pm 0.6$ & $9.7 \pm 0.04$ \\
$\mathrm{D}$ & $7.5 \pm 1.9$ & $5.7 \pm 1.3$ & $11.9 \pm 0.9^{*}$ & $5.2 \pm 0.7$ & $9.5 \pm 0.04$ \\
$\mathrm{E}$ & $16.7 \pm 1.4$ & $16.4 \pm 1.6$ & $21.5 \pm 1.2^{*}$ & $14.3 \pm 1.3$ & $9.3 \pm 0.04$ \\
$\mathrm{~F}$ & $31.9 \pm 2.8$ & $38.9 \pm 1.8^{*}$ & $27.9 \pm 0.6$ & $41.6 \pm 1.2^{*}$ & $9.2 \pm 0.03$ \\
$\mathrm{G}$ & $22.9 \pm 1.3^{*}$ & $17.1 \pm 0.9$ & $15.5 \pm 1.2$ & $14.5 \pm 1.0$ & $9.0 \pm 0.03$ \\
$\mathrm{H}$ & $2.3 \pm 0.6$ & $2.7 \pm 0.5$ & $4.1 \pm 0.5^{*}$ & $4.4 \pm 0.5^{*}$ & $<9.0->7.0$ \\
$\mathrm{Z}$ & $14.8 \pm 0.8$ & $15.2 \pm 1.0$ & $12.3 \pm 0.9^{*}$ & $15.6 \pm 0.3$ & $\leqslant 7.0$ \\
\hline
\end{tabular}

Values represent mean percentages $\pm \operatorname{SEM}$ for each isoform. Intact $(n=3)$; Intact-I $(n=3)$; Castrate $(n=6)$; Castrate-I $(n=6)$. Means within a row with asterisks are significantly different from those without asterisks $(P<0.05)$.

${ }^{2}$ Values represent mean elution $\mathrm{pH} \pm \operatorname{SEM}$ for each isoform $(n=18)$.

Multiple isoforms of $\mathrm{LH}$ are thought to be attributable, in part, to varying oligosaccharide structures that reside on both subunits of the LH molecule (Baenziger and Green, 1988; Grotjan, 1989). High mannose oligosaccharides are attached to subunit peptides during translation. Post-translational modification of the oligosaccharides, including sulfation in sheep, contributes to the heterogeneity. Nine isoforms of LH could be identified in all treatment groups when pituitary extracts were analysed by chromatofocusing on $\mathrm{pH} 10.5-7.0$ gradients. This pattern is analogous to those previously reported for sheep (Grotjan et al., 1991; Keel et al., 1987; Zalesky and Grotjan, 1991a) and cows (Zalesky and Grotjan, 1991a, b; Stumpf et al., 1992a, b). However, it should be noted that more than nine isoforms of $\mathrm{LH}$ are present in ovine or bovine pituitaries because peak $Z$ consists of approximately five isoforms which elute in the acidic range if the chromatofocusing gradients are extended below pH 7.0 to 4.0 (Keel et al., 1990; Stumpf et al., 1992). In earlier studies from this laboratory, some LH eluted as a flow through peak when ovine pituitary extracts were chromatofocused on $\mathrm{pH}$ 10.5-7.0 gradients (for example, see Keel et al., 1987). More recent studies have established that the PBE-118 resin exhibits a reduced binding capacity at high $\mathrm{pH}$ (Grotjan et al., 1991). Hence, the chromatofocusing method was revised such that the samples were applied in the elution buffer. Under the revised conditions, LH binds quantitatively to the resin. However, a basic form of $\mathrm{LH}$ which elutes after the flow through peak but before peak $B$ (i.e. is minimally retarded) becomes apparent (Grotjan et al., 1991). This peak is coded as $\mathrm{A}^{\prime}$ herein to provide a unique designation (see Grotjan et al., 1991 for additional details).

The percentage of $\mathrm{LH}$ present as the two most basic isoforms, $A^{\prime}$ and $B$ (representing approximately $2.0 \%$ of the intrapituitary LH), was unaffected by treatment. These forms are released in minimal quantities and Zalesky and Grotjan (1991b) proposed that they represent early processing intermediates found primarily within the pituitary gland. The intrapituitary LH of wethers contained higher percentages of isoforms C, D and $\mathrm{E}$ as well as a lower percentage of isoform $\mathrm{Z}$ (comparing castrate with intact). The results of this and previous (Keel et al., 1987; Stumpf et al., 1992a) studies are consistent in that castration shifted the distribution of intrapituitary LH towards basic forms. Intrapituitary LH represents the net result of biosynthesis and secretion. The LH released from the ovine pituitary in vitro consists of lower percentages of LH isoforms C, D and $E$ as well as higher percentages of isoforms $F$ and $G$ relative to that found in the tissue (Zalesky and Grotjan, 1991b). Thus, the higher percentages of basic forms in the pituitaries of castrates, which have high secretion rates for $\mathrm{LH}$, can be attributed to enhanced release of isoforms $F$ and $G$ and, perhaps, an overall increased rate of LH synthesis under the assumption that basic forms represent the more immature forms of LH.

LHRH immunoneutralization consistently and markedly reduced the amount of $\mathrm{LH}$ in the pituitary regardless of the presence of the testes. Comparison of the distribution of $\mathrm{LH}$ among its isoforms in immunized rams and wethers revealed that patterns of isoforms were similar. The only difference was that the immunized wethers had a higher percentage of isoform $\mathrm{H}$. This observation suggests a small or minor interaction between hypothalamic LHRH and gonadal steroids in establishing the distribution of $\mathrm{LH}$ among its isohormones. Nevertheless, the overall similarity of patterns in immunized animals suggests that hypothalamic influences clearly predominate.

When the distribution of isoforms was compared between immunized and non-immunized animals (intact and castrate versus intact-I and castrate-I), the major difference that emerged was that the immunized animals had higher percentages of isoform F. A similar experiment performed in cows yielded almost identical results (Stumpf et al., 1992b). The higher percentages of isoform $\mathrm{F}$ in immunized rams, wethers and cows may be attributable to blockage of LHRH-stimulated $\mathrm{LH}$ release resulting in the specific accumulation of this isoform. Moreover, this observation is of particular interest from a physiological perspective. Isoform $\mathrm{F}$ is the predominant molecular form of $\mathrm{LH}$ in sheep pituitaries (Keel et al., 1987; Zalesky and Grotjan, 1991a, b) and cattle (Zalesky and Grotjan, 1991a, b; Stumpf et al., 1992a, b) constituting up to $50 \%$ of the LH present. Furthermore, isoform $\mathrm{F}$ is selectively secreted (Zalesky and Grotjan, 1991b) and has the highest biological potency among the isoforms of ovine (Keel et al., 1987) and bovine LH (Stumpf et al., 1992a). These lines of evidence suggest that isoform $F$ is likely to be the pre-eminent molecular form in mediating the 
actions of LH. Hence, changes in the percentage of LH present as isoform $\mathrm{F}$ are likely to be particularly meaningful.

In summary, rams and wethers actively immunized against LHRH had markedly reduced amounts of LH in their pituitaries as well as changes in the distribution of $\mathrm{LH}$ among its isoforms yielding greater percentages of isoform $\mathrm{F}$. Thus, hypothalamic LHRH not only maintains the quantity of LH in the pituitary but also influences the distribution of $\mathrm{LH}$ among its isoforms and reduces the percentage present as isoform $\mathrm{F}$. A portion of this effect can be attributed to selective secretion. This study also confirms that gonadal hormones control the distribution of isoforms of $\mathrm{LH}$ and suggests a minor interaction between LHRH and gonadal steroids in modulating the pattern of intrapituitary $\mathrm{LH}$ isoforms although hypothalamic influences clearly predominate. The exact points in biosynthesis and secretion where hypothalamic LHRH and gonadal steroids exert their controlling actions remain to be elucidated.

This report is published as paper No. 9616, Journal Series, Nebraska Agricultural Research Division. The research was supported in part by NIH grant HD 18879 and NSF grant DCB-9104968. Appreciation is expressed to L. Rife for her assistance in preparation of this manuscript. The authors are also grateful to D. N. Ward and L. E. Reichert, Jr, who provided purified oLH.

\section{References}

Andrews WV, Maurer RA and Conn PM (1988) Stimulation of rat luteinizing hormone- $\beta$ messenger RNA levels by gonadotropin releasing hormone Joumal of Biological Chemistry 263 13755-13761

Baenziger JU and Green ED (1988) Pituitary glycoprotein hormone oligosaccharides: structure, synthesis and function of the asparagine-linked oligosaccharides on lutropin, follitropin and thyrotropin Biochimica et Biophysica Acta 947 287-306

Chappel SC, Ellinwood WE. Huckins C, Herbert DC and Spies HG (1980) Active immunization of male rhesus monkeys against luteinizing hormone releasing hormone Biology of Reproduction 22 333-342

Chase DJ, Schanbacher BD and Lunstra DD (1988) Effects of pulsatile and continuous luteinizing hormone $(\mathrm{LH})$ infusions on testosterone responses to $\mathrm{LH}$ in rams actively immunized against gonadotropin-releasing hormone Endocrinology 123 816-826

Clarke IJ, Fraser HM and McNeilly AS (1978) Active immunization of ewes against luteinizing hormone releasing hormone, and its effects on ovulation and gonadotrophin, prolactin and ovarian steroid secretion journal of Endocrinology $\mathbf{7 8}$ 39-47

Day ML, Imakawa K, Garcia-Winder M, Zalesky DD, Schanbacher BD, Kittok RJ and Kinder JE (1984) Endocrine mechanisms of puberty in heifers: estradiol negative feedback regulation of luteinizing hormone secretion Biology of Reproduction 31 332-341

D'Occhio MJ, Schanbacher BD and Kinder JE (1983) Androgenic and oestrogenic steroid participation in feedback control of luteinizing hormone secretion in male sheep Acta Endocrinologia 102 499-504
Falvo RE, Chandrashekar V, Arthur RD, Kuensther AR, Hasson T, Awoniyi C and Schanbacher BD (1986) Effect of active immunization against LHRH or LH in boars: reproductive consequences and performance traits Journal of Animal Science 63 986-994

Grotjan HE, Jr (1989) Oligosaccharide structures of the anterior pituitary and placental glycoprotein hormones. In Microheterogeneity of Glycoprotein Hormones pp 23-52 Eds BA Keel and HE Grotjan, Jr CRC Press, Boca Raton

Grotjan HE, Schanbacher BD and Keel BA (1991) Ovine luteinizing hormone V: significance of flow through peaks observed during chromatofocusing as revealed by various methods of sample preparation and application Journal of Chromatography 549 141-152

Imakawa K, Day ML, Zalesky DD, Garcia-Winder M, Kittok RJ and Kinder JE (1986) Regulation of pulsatile LH secretion by ovarian steroids in the heifer Journal of Animal Science 63 162-168

Keel BA, Schanbacher BD and Grotjan HE, Jr (1987) Ovine luteinizing hormone. I. Effects of castration and steroid administration on the charge heterogeneity of pituitary luteinizing hormone Biology of Reproduction 36 1102-1113

Keel BA, Harms RL and Grotjan HE, Jr (1990) Characterization of the acidic forms of ovine pituitary luteinizing hormone Acta Endocrinologica 123 $563-570$

Landefeld TD, Bangnell T and Levitan I (1989) Effects of estradiol on gonadotropin subunit messenger ribonucleic acid amounts during an induced gonadotropin surge in anestrous ewes Molecular Endocrinology 3 10-14

Mercer JE, Clements JA, Funder JW and Clarke I) (1988) Luteinizing hormone- $\beta$ mRNA levels are regulated primarily by gonadotropin-releasing hormone and not by negative estrogen feedback on the pituitary Neuroendocrinology 47 563-566

SAS (1985) User's Guide: Statistics. SAS Inst Inc., Cary, NC

Schally AV, Arimura A and Kastin AJ (1973) Hypothalamic releasing hormones: at least nine substances from the hypothalamus control the secretion of pituitary hormones Science $179341-350$

Schanbacher BD (1982) Responses of ram lambs to active immunization against testosterone and luteinizing hormone releasing hormone American Journal of Physiology 242 E201-E205

Schanbacher BD and Ford JJ (1977) Gonadotropin secretion in cryptorchid and castrate rams and the acute effects of exogenous steroid treatment Endocrinology $100387-393$

Snedecor GW and Cochran WG (1967) Statistical Methods (6th edn). Iowa State University Press, Ames

Stumpf TT, Roberson MS, Wolfe MW, Zalesky DD, Cupp AS, Werth LA, Kojima N, Hejl K, Kittok RJ, Grotjan HE and Kinder JE (1992a) A similar distribution of gonadotropin isohormones is maintained in the pituitary throughout sexual maturation in the heifer Biology of Reproduction 46 442-450

Stumpf TT, Wolfe MW, Roberson MS, Caddy G, Kittok R\}, Schanbacher BD, Grotjan HE and Kinder JE (1992b) Bovine luteinizing hormone (LH) isoforms and amounts of messenger ribonucleic acid for alpha- and LH beta-subunits in pituitaries of cows immunized against LH-releasing hormone Biology of Reproduction 47 776-781

Wise ME, Nilson JH, Nejedlik MT and Nett TM (1985) Measurement of messenger RNA for luteinizing hormone $\beta$-subunit and $\alpha$-subunit during gestation and the postpartum period in ewes Biology of Reproduction 33 1009-1015

Zalesky DD and Grotjan HE (1991a) Luteinizing hormone in the bovine pars tuberalis: secretion in response to luteinizing hormone releasing hormone and intracellular isoforms Domestic Animal Endocrinology 8 179-187

Zalesky DD and Grotjan HE (1991b) Comparison of intracellular and secreted isoforms of bovine and ovine luteinizing hormone Biology of Reproduction 44 1016-1024 